\title{
EFFECTS OF REDUCED GLOMERULAR FILTRATION ON URINE CONCENTRATION IN THE PRESENCE OF ANTIDIURETIC HORMONE *
}

\author{
By NORMAN G. LEVINSKY, DOUGLAS G. DAVIDSON AND ROBERT W. BERLINER \\ WITH THE TECH NICAL ASSISTANCE OF AGNES S. PRESTON \\ (From the Laboratory of Kidney and Electrolyte Metabolism, National Heart Institute, \\ Bethesda, Md.)
}

(Submitted for publication October 10, 1958; accepted January 2, 1959)

In the presence of antidiuretic hormone $(\mathrm{ADH})$, the concentration of the urine is usually related inversely to the excreted osmotic load. When solute excretion is increased by infusion of relatively nonreabsorbable solute, urine concentration falls toward plasma concentration. Maximum urine concentrations are achieved only when solute excretion is very low. In the dog, the highest urine osmolalities, in the range of 1,800 to 2,200 mOsm. per $\mathrm{Kg} . \mathrm{H}_{2} \mathrm{O}$, occur when solute excretion is about 200 to $300 \mu \mathrm{Osm}$. per minute. If urine concentration and solute excretion are inversely related even at the lowest solute loads, one would expect an increase in urine concentration when spontaneously low osmotic loads are decreased further by lowering the glomerular filtration rate (GFR). On the other hand, if the highest urine concentrations seen under spontaneous conditions represent the maximum osmolality which the kidney can achieve (1), further reductions in solute excretion would not be expected to result in increased urine concentration. Under certain circumstances in the present studies, maximum spontaneous urine concentrations did increase when the GFR was reduced, in conformity with the first view described.

However, neither of these alternatives explains the findings of Leaf, Kerr, Wrong and Chatillon (2), confirmed in this paper, that urine osmolality often falls when the GFR is reduced in the presence of ADH. Recently, it has been postulated $(3,4)$ that urine is made hypertonic to plasma by equilibration with hypertonic interstitial fluid in the medulla of the kidney. This paper presents data consistent with the view that the fall in urine concentration when GFR is reduced is due to de-

* This paper was presented in summary form at the Annual Meeting of the American Society for Clinical Investigation, May 5, 1958. creased delivery to the medulla of the sodium salts and urea necessary to maintain hypertonicity of the interstitial fluid. In particular, the data support the hypothesis that urea plays a unique role in the concentrating mechanism.

\section{METHODS}

Studies were performed on female mongrel dogs weighing 16 to $22 \mathrm{Kg}$. The dogs were prepared for repeated use by positioning an inflatable silicone rubber cuff surgically around the right renal artery to permit acute, graded, reversible reduction of the GFR in the right kidney. Urine was collected separately from each kidney by means of a bladder-splitting operation. This surgical preparation $^{1}$ has been described in detail elsewhere (5).

The dogs were unanesthetized and trained to stand quietly, partially supported by slings. Water and food were withheld during the 24 to 48 hours prior to each experiment. In addition, 50 or $100 \mathrm{mU}$ per $\mathrm{Kg}$. per hour of vasopressin (Pitressin $(8)$ ) was given in the intravenous infusions throughout each experiment. The $\mathrm{pH}$ of the infusions was adjusted to 5.2 to 5.6 with acetic acid to assure stability of the vasopressin during the course of the experiment. For experiments in which minimal solute excretion was desired, the vasopressin, inulin and $p$-aminohippurate $(\mathrm{PAH})$ were dissolved in water or 0.45 per cent saline and infused at rates of less than 0.5 ml. per minute by means of a constant infusion pump. For experiments involving osmotic diuresis, the vasopressin, inulin and $\mathrm{PAH}$ were added to hypertonic (6 to 10 per cent) mannitol in water or urea in 0.9 per cent saline, and the infusions were administered at appropriate rates (usually 4 to $6 \mathrm{ml}$. per minute). Collection periods were begun by attaching a short length of rubber tubing to the funnel in each half-bladder and stopped by removing the tubing. Therefore, a short interval elapsed between collection periods. The urine was allowed to drain freely into graduates during each period.

In experiments in which kidney tissue was analyzed, several consecutive collection periods with stable urine flow and osmolality were obtained immediately before the kidneys were removed. The dog was killed with

$1 \mathrm{We}$ are indebted to Dr. Clarence Weldon and Dr. John Holman for the surgical preparations. 
pentobarbital given rapidly intravenously in a dose sufficient to cause circulation to stop within a few seconds. The kidneys were removed from the animal within two minutes after death. The brown cap of cortex and the reddish outer medulla (strictly, the outer stripe of the outer medulla) were identified by gross anatomic characteristics and random pieces were taken for analysis. Serial sections of the (inner) medulla, from the papillary crescent toward the cortex, were cut freehand with a large, flat blade. The plane of the sections was perpendicular to the axis of the medulla. The first section, about $3 \mathrm{~mm}$. thick, including the crescent and trimmed at the ends of the area cribrosa, was arbitrarily designated the papilla for purposes of these analyses. The next serial section, $3 \mathrm{~mm}$. in thickness, was discarded. The section thereafter, also about $3 \mathrm{~mm}$. thick, trimmed just within the red stripe of outer medulla, was called the inner medulla.2 The pieces of inner medulla and papilla used weighed approximately 200 to $250 \mathrm{mg}$. Each tissue was weighed and homogenized in 10 or $15 \mathrm{ml}$. of demineralized water. The homogenate was divided immediately into two parts. The portion for urea analysis was centrifuged and aliquots of the supernatant were taken for analysis. The portion for electrolyte analysis was heated at $100^{\circ} \mathrm{C}$. for one hour before centrifugation. Aliquots of the supernatant were then taken for sodium, potassium and chloride analysis. Other pieces of tissue from each area of the kidney were dried to constant weight under vacuum to permit calculation of tissue water as per cent of wet weight. Urea analysis was performed in duplicate by the micro-diffusion method of Conway (7); an ammonia blank was determined for each sample. Other methods of analysis used in this laboratory have been listed elsewhere (5).

\section{RESULTS}

Before each experiment, two or three preliminary collection periods were obtained to ascertain that urine osmolalities and filtration rates were comparable on the two sides. Dogs were not used if the two kidneys differed in these respects by more than about 10 per cent. The surgical preparation permitted the use of the left kidney as a simultaneous control for the right during periods in which the filtration rate of the right kidney was reduced. Spontaneous variations in urine concentration and GFR were frequent in both kidneys during preliminary periods and in the control kid-

2 The exact concentration gradients of urea and sodium in the medulla are not delineated well by this method, since relatively thick, nonconsecutive slices of tissue are used. However, the method is suitable and convenient for comparing concentrations in different kidneys. The use of thin, consecutive slices, as described by Ullrich and Jarausch (6), gives more precise information about concentration patterns in the medulla. ney during periods when the cuff was inflated. No attempt has been made to account for these variations. The assumption is made that spontaneous changes affect both kidneys equally and that therefore the best control for the right kidney when its filtration rate is reduced is the simultaneous behavior of the unoperated left kidney. For this reason, data in summary charts are presented in terms of the ratios of the urine osmolalities or filtration rates of the two kidneys.

Data from 17 experiments performed on 12 different dogs during low solute excretion are presented in this fashion by the solid dots in Figure 1. When the GFR of the right kidney was reduced below that of the control kidney by 30 per cent or less, the urine from the right kidney usually became more concentrated than that from the control. Regularly with decreases of more than 30 per cent, and sometimes with lesser decreases in filtration rate, urine from the right kidney became much less concentrated than the urine from the control kidney. The osmolality of urine from the

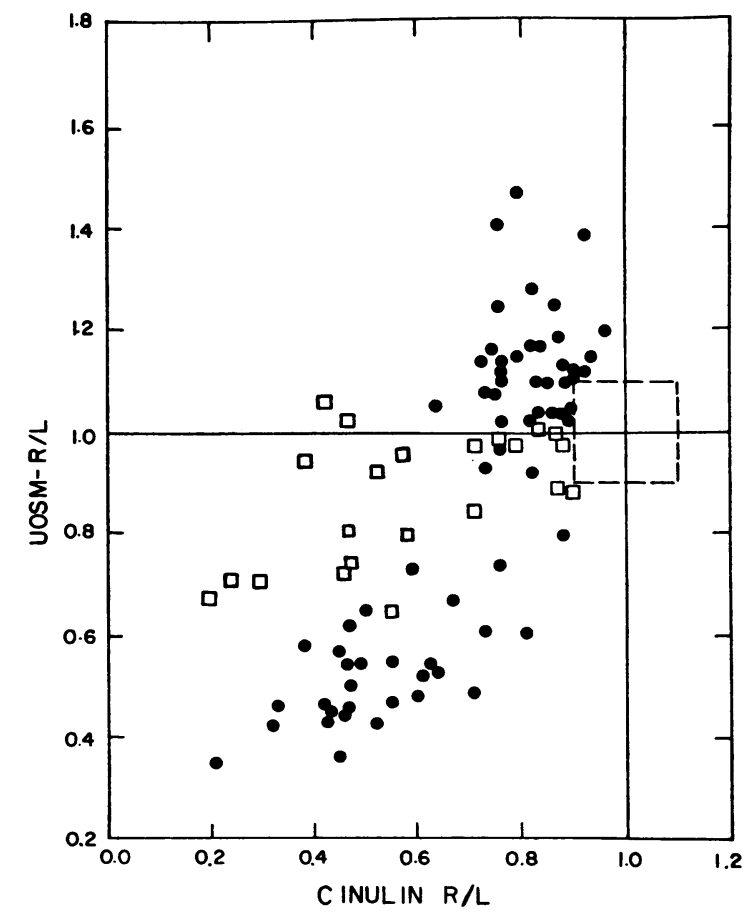

Fig. 1. Changes in Urine Concentration When THE GFR Is Reduced at Low Solute ExcRetion IN Dogs on a Regular Diet (O) and in Dogs on a Low Protern Diet ( $\square$ )

The dashed lines circumscribe the area in which data from all the preliminary periods fall. 


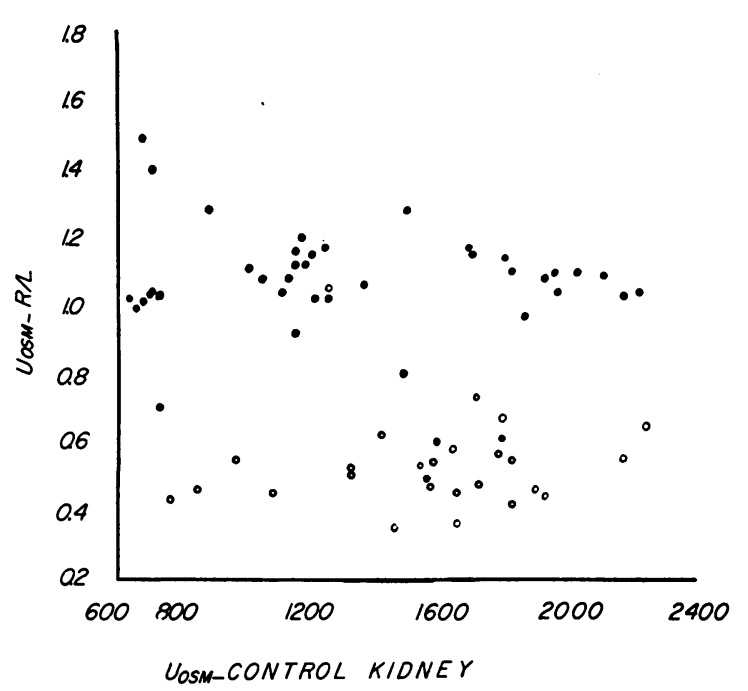

Fig. 2. Changes in Urine Concentration as a Function of THE OSMOLALITY OF THE URINE FROM THE Control Kidney, During Reduction of the GFR at Low Solute Excretion in Dogs on a Regular Diet

The clearance periods represented are the same as those shown by solid dots in Figure 1. The open circles in this figure represent periods in which the ratio of the filtration rates of the two kidneys was less than 0.7 ; the solid dots represent periods in which this ratio was 0.7 or more.

control kidney in this group of experiments varied from 650 to $2,000 \mathrm{mOsm}$. per $\mathrm{Kg}$. $\mathrm{H}_{2} \mathrm{O}$. The results of experiments throughout this range of concentrations were comparable, as is shown in Figure 2.

The protocol of an experiment in which a small relative reduction in GFR resulted in an absolute rise in urine osmolality is presented in Table $\mathrm{I}$. The preliminary periods of this experiment are an example of the spontaneous changes in urine osmolality frequently seen in dehydrated dogs during these studies. The variations in urine concentration of both kidneys during these periods and in the control kidney during the experimental periods cannot be related to changes in solute excretion and no adequate explanation for them can be offered. These preliminary periods are therefore not to be construed as "control" periods, but do indicate that the function of the two kidneys was nearly equal. When the cuff around the right renal artery was inflated, a reduction of about 15 per cent in the GFR of the right kidney relative to the left was obtained. The osmolality of the urine from the control kidney was in the range of the highest spontaneous concentrations found in dehydrated dogs. Nevertheless, the small reduction in GFR of the right kidney resulted in a further increase in urine concentration. Immediately after the last period, the dog was killed and the kidneys removed for analysis. Urea, sodium, potassium and chloride concentrations were comparable in the two kidneys.

The protocol of a similar experiment is presented in Table II. During the preliminary periods, the function of the two kidneys was nearly equal. The cuff around the right renal artery was then inflated, and after a considerable period of adjustments, a fairly stable reduction in the GFR of the right kidney was obtained. Even at the very high urine osmolalities in this experiment, a reduction of 10 to 25 per cent in GFR resulted in a concentration difference of some 75 to 250 mOsm. per $\mathrm{Kg} . \mathrm{H}_{2} \mathrm{O}$ between the urine from the two kidneys. Urea concentration was somewhat greater in the papilla from the right kidney, which had excreted the more concentrated urine, than in the control papilla. Sodium, potassium and chloride concentrations were comparable in the two kidneys. Kidney analyses comparable to those obtained in these experiments were found in two dogs in which imperfect placement of the renal artery cuff resulted in a small chronic reduction in GFR and increased urine concentration in the right kidney.

In Table III, data are given from an experiment in which reduction of the GFR resulted in a decrease in urine concentration. After the cuff around the right renal artery was inflated, a stable reduction of about 50 per cent was obtained in the GFR of the right kidney as compared to the control kidney. Urine concentration from the right kidney fell to less than half the value for the left. A large part of the fall in urine osmolality was due to the fall in urine urea concentration. Analysis of kidney tissue showed marked reduction in urea concentration and small decreases in sodium and chloride concentration in the right papilla as compared to the left. Qualitatively similar data were obtained in three other experiments and from three dogs in which an imperfectly positioned artery cuff chronically reduced urine concentration and GFR in the right kidney. In some of these experiments, however, especially those in which the decrease in GFR was more than 50 
DECREASED GFR AND URINE CONCENTRATION

TABLE I

Reduction of glomerular filtration rate with increase in urine osmolality

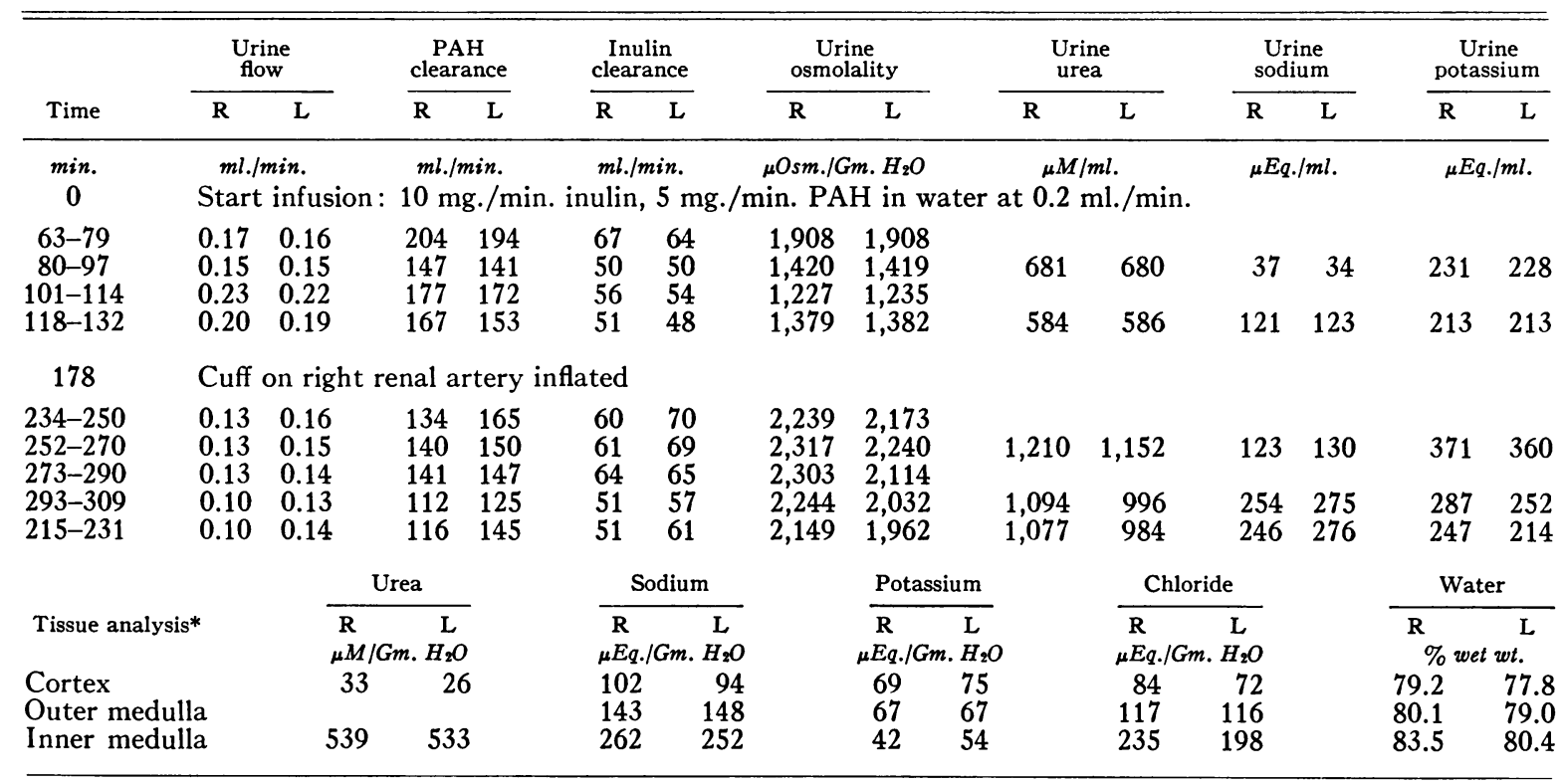

* Values for papilla invalidated by technical error.

per cent, the sodium concentration of the right papilla was reduced more markedly (20 to 40 per cent less than the left papilla) than in the experiment shown in Table III. In all these cases, the reduction in tissue urea concentration was proportionately much greater than the decrease in tissue sodium concentration.
From these experiments it seemed probable that decreases in urine concentration during reduction in GFR were related to decreased delivery of urea and sodium to the medulla. During osmotic diuresis due to infusion of urea, relatively large amounts of urea and sodium appear in the urine, even when the GFR is reduced. It therefore was

TABLE II

Reduction of glomerular filtration rate with increase in urine osmolality

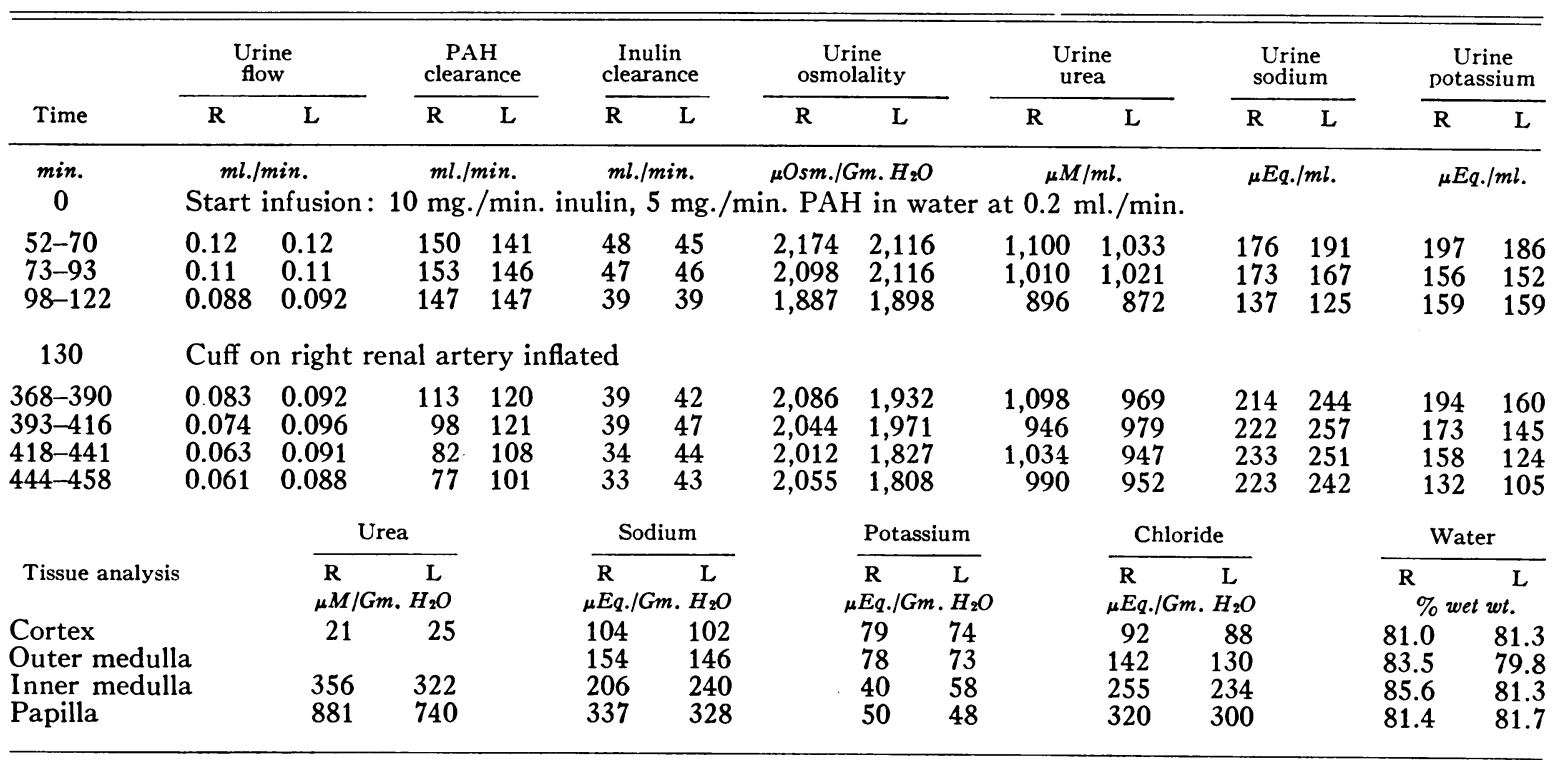


TABLE III

Reduction of glomerular filtration rate with decrease in urine osmolality

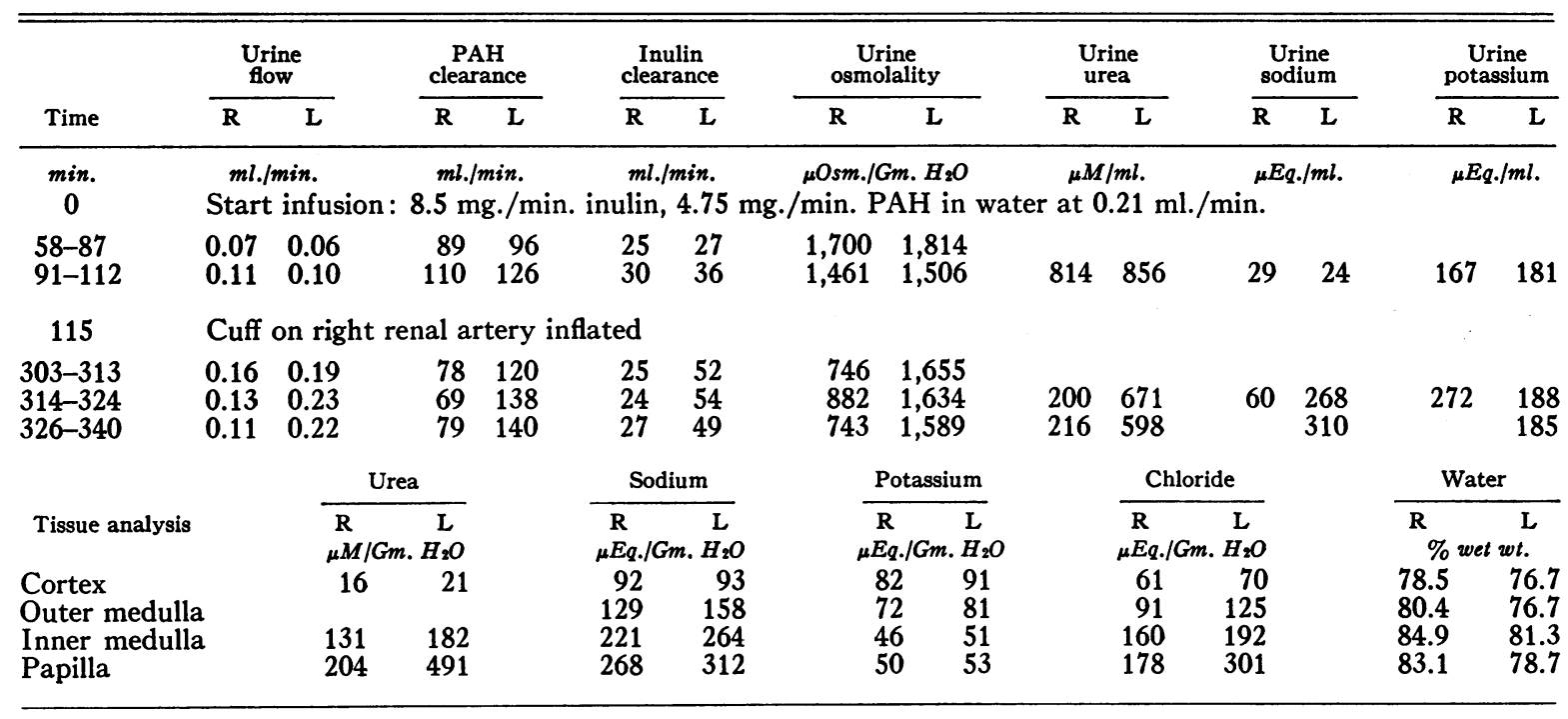

a reasonable assumption that delivery of urea and sodium to the medulla is adequate during urea diuresis even when filtration is restricted. During mannitol diuresis, urinary sodium excretion is increased and the concentration of urea in the urine is so low as to contribute an insignificant fraction of total urinary osmolality. It might be expected, therefore, that adequate amounts of sodium would reach the medulla even when the GFR is reduced during mannitol diuresis, and that changes in urea concentration could result only in minimal changes in urine osmolality. From these considerations, there should be no fall in urine osmolality when the GFR is reduced during urea or mannitol diuresis.

The results of five experiments in five different dogs during mannitol diuresis and three experiments in two different dogs during urea diuresis are plotted in Figure 3. Osmolality of the urine from the control kidney was from 350 to 550 mOsm. per $\mathrm{Kg} . \mathrm{H}_{2} \mathrm{O}$ in the mannitol experiments, and from 450 to 650 when urea was given. Even

TABLE IV

Reduction of glomerular filtration rate during urea diuresis

\begin{tabular}{|c|c|c|c|c|c|c|c|c|c|c|c|c|c|c|}
\hline \multirow[b]{2}{*}{ Time } & \multicolumn{2}{|c|}{$\begin{array}{l}\text { Urine } \\
\text { flow }\end{array}$} & \multicolumn{2}{|c|}{$\underset{\text { clearance }}{\text { PAH }}$} & \multicolumn{2}{|c|}{$\begin{array}{c}\text { Inulin } \\
\text { clearance }\end{array}$} & \multicolumn{2}{|c|}{$\begin{array}{c}\text { Urine } \\
\text { osmolality }\end{array}$} & \multicolumn{2}{|c|}{$\begin{array}{l}\text { Urine } \\
\text { urea }\end{array}$} & \multicolumn{2}{|c|}{$\begin{array}{c}\text { Urine } \\
\text { sodium }\end{array}$} & \multicolumn{2}{|c|}{$\begin{array}{c}\begin{array}{c}\text { Urine } \\
\text { potassium }\end{array} \\
\end{array}$} \\
\hline & $\mathbf{R}$ & $\overline{\mathbf{L}}$ & $\mathbf{R}$ & $\mathbf{L}$ & $\mathbf{R}$ & $\bar{L}$ & $\mathbf{R}$ & $\mathrm{L}$ & $\mathbf{R}$ & $\mathbf{L}$ & $\mathbf{R}$ & $\mathbf{L}$ & $\overline{\mathbf{R}}$ & $\mathrm{L}$ \\
\hline $\begin{array}{c}\min . \\
0\end{array}$ & \multicolumn{2}{|c|}{$\begin{array}{l}\text { ml./min. } \\
\text { Start infusi } \\
2,650 \mu \mathrm{M}\end{array}$} & \multicolumn{2}{|c|}{ ml./min. } & mbl./ & $\begin{array}{l}\text { iin. } \\
4.8 \\
\text { ee at }\end{array}$ & $\begin{array}{l}\mu O s m . / G \\
/ \mathrm{min} . \mathrm{F} \\
\mathrm{ml} . / \mathrm{mi}\end{array}$ & $\begin{array}{l}\text { n. } \mathrm{H}_{2} \mathrm{O} \\
\mathrm{AH}, 10 \\
\text { l. }\end{array}$ & $\stackrel{\mu M}{\mathrm{mU} / \mathrm{I}}$ & gl. & \multicolumn{2}{|c|}{$\begin{array}{r}\mu E q . / m l . \\
\text { sopressin, }\end{array}$} & \multicolumn{2}{|c|}{$\mu E q . / m l}$. \\
\hline $\begin{array}{l}55-61 \\
62-67 \\
69-74\end{array}$ & $\begin{array}{l}1.7 \\
1.7 \\
1.8\end{array}$ & $\begin{array}{l}1.8 \\
1.8 \\
2.0\end{array}$ & $\begin{array}{l}187 \\
200 \\
124\end{array}$ & $\begin{array}{l}127 \\
176\end{array}$ & $\begin{array}{l}70 \\
73 \\
71\end{array}$ & $\begin{array}{l}71 \\
75 \\
72\end{array}$ & $\begin{array}{l}775 \\
769 \\
716\end{array}$ & $\begin{array}{l}764 \\
743 \\
694\end{array}$ & 418 & 382 & 106 & 106 & 54 & 48 \\
\hline 75 & \multicolumn{14}{|c|}{ Cuff on right renal artery inflated } \\
\hline $\begin{array}{l}249-255 \\
257-262 \\
263-267\end{array}$ & $\begin{array}{l}1.1 \\
1.2 \\
1.2\end{array}$ & $\begin{array}{l}5.0 \\
5.2 \\
5.3\end{array}$ & $\begin{array}{l}265 \\
270 \\
280\end{array}$ & $\begin{array}{l}286 \\
289\end{array}$ & $\begin{array}{l}49 \\
45 \\
49\end{array}$ & $\begin{array}{l}67 \\
55 \\
71\end{array}$ & $\begin{array}{l}975 \\
924 \\
972\end{array}$ & $\begin{array}{l}605 \\
612 \\
612\end{array}$ & 858 & 332 & 22 & 130 & 32 & 23 \\
\hline 268 & \multicolumn{14}{|c|}{ Cuff pressure increased } \\
\hline $\begin{array}{l}274-279 \\
281-286 \\
288-293\end{array}$ & $\begin{array}{l}0.52 \\
0.73 \\
0.81\end{array}$ & $\begin{array}{l}5.2 \\
5.5 \\
5.5\end{array}$ & $\begin{array}{l}174 \\
222 \\
204\end{array}$ & $\begin{array}{l}314 \\
414\end{array}$ & $\begin{array}{l}26 \\
39 \\
43\end{array}$ & $\begin{array}{l}62 \\
66 \\
61\end{array}$ & $\begin{array}{r}1,040 \\
1,016 \\
985\end{array}$ & $\begin{array}{l}618 \\
614 \\
618\end{array}$ & 890 & 334 & 6 & 136 & 26 & 26 \\
\hline
\end{tabular}


TABLE V

Reduction of glomerular filtration rate during mannitol diuresis

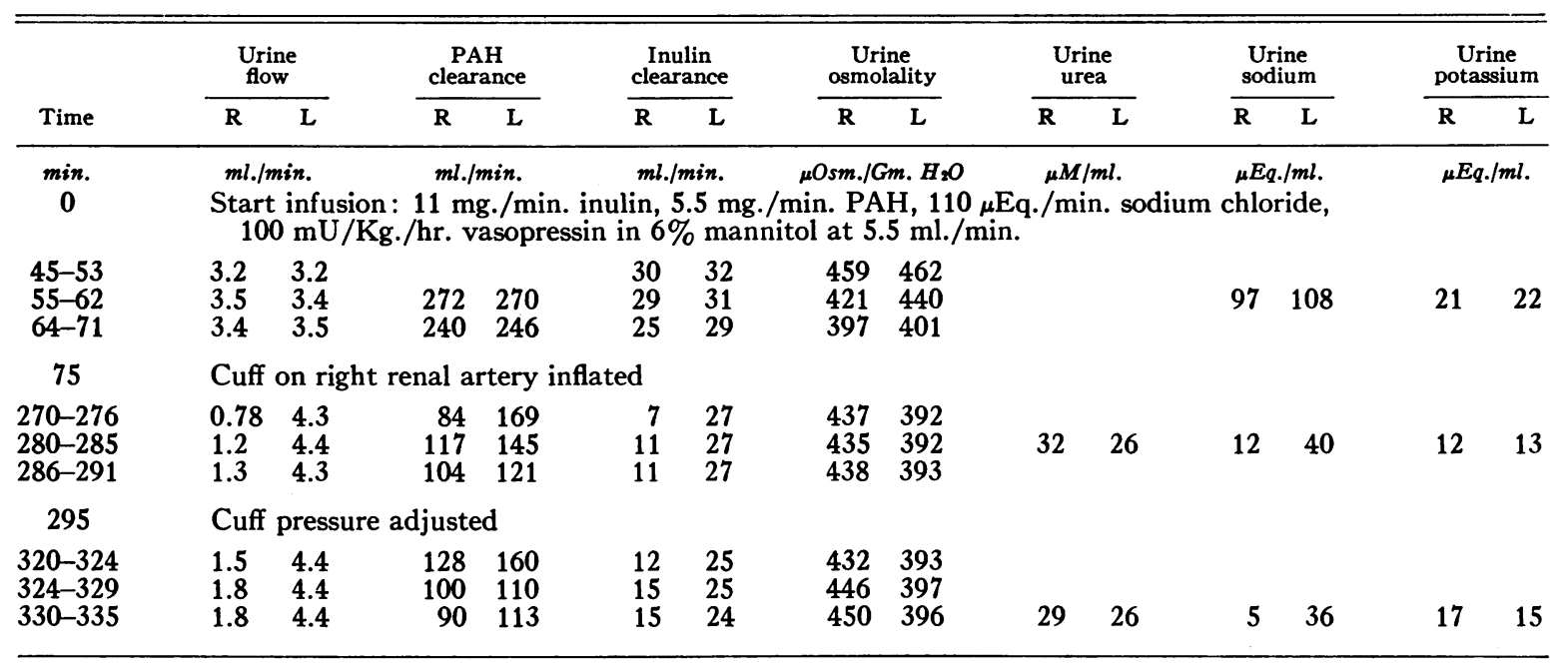

when the GFR of the right kidney was reduced as much as 90 per cent during urea diuresis and 60 per cent during mannitol diuresis, urine from the right kidney regularly became more concentrated than that from the control kidney. When urea was administered, the increases in urine concentration were often very striking and regularly greater than those occurring during mannitol diuresis. An example of an experiment with urea infusion is given in Table IV and a representative experiment in which mannitol was given is shown in Table V. In the experiment shown in Table IV, the preliminary periods show approximate equality of kidney function. During the first group of three periods after the artery cuff was inflated, the GFR of the right kidney was reduced some 20 to 30 per cent. When cuff pressure was increased, GFR was decreased 30 to 60 per cent. In both groups of periods, urine from the right kidney was 50 to 60 per cent more concentrated than that from the left. The concentration difference in urea between the urines from the two kidneys was greater than the difference in urine osmolality. In the experiment shown in Table $\mathrm{V}$, reductions in the GFR of the right kidney of from 40 to 75 per cent resulted in increases of 10 to 15 per cent in the concentration of the urine from the right kidney as compared to the control. Urine urea concentrations accounted for only some 5 to 7 per cent of the total osmolality of the urine from either kidney. These results during osmotic diu- resis, in which urine concentration regularly rose at all degrees of reduction of the GFR, are to be contrasted with those during low solute excretion, in which urine concentration always fell when GFR was decreased more than 30 per cent (Figure 1).

In five experiments on four dogs, the urea concentration in urine from the control kidney during maximum dehydration was decreased to between 40 and $150 \mu \mathrm{M}$ per ml. by keeping the dogs on a low protein diet for one to two weeks. These dogs were then studied without solute diuresis, in a manner analogous to the dehydrated dogs on regular diets. As is shown by the open squares in Figure 1, reductions of filtration rate resulted in smaller falls in urine concentration than did comparable reductions in dogs on regular diets. The osmolality of the urines from the control kidney varied from 400 to $900 \mathrm{mOsm}$. per $\mathrm{Kg} . \mathrm{H}_{2} \mathrm{O}$ in the low protein experiments. In these experiments, control urea concentrations were already so low that even complete disappearance of urea from the urine during reductions in GFR could effect little change in urine osmolality. In this respect, the experiments are analogous to those during mannitol diuresis. However, no diuretic was present in these experiments to decrease proximal sodium reabsorption, and delivery of sodium to the medulla was therefore probably restricted.

Animals were not sacrificed to obtain kidney analyses in the experiments involving osmotic diu- 
TABLE VI

Kidney analysis during low protein diet, mannitol diuresis and urea diuresis

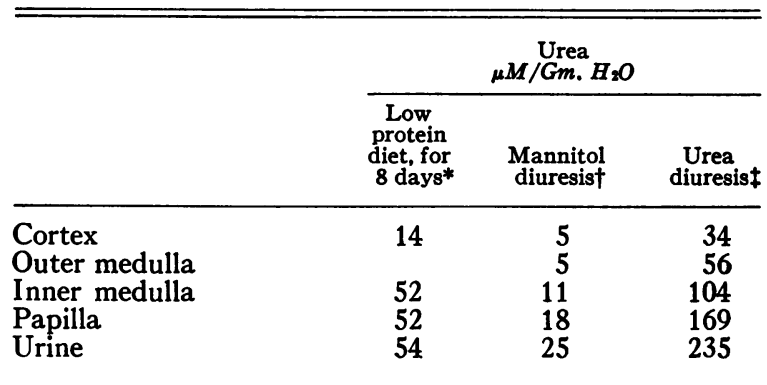

* Dog on low protein diet: urine flow, $0.1 \mathrm{ml} . / \mathrm{min}$.; osmolality, $506 \mathrm{mOsm}$. per $\mathrm{Kg}$. $\mathrm{H}_{2} \mathrm{O}$.

$\dagger$ Dog during mannitol diuresis: urine flow, 4.1 ; osmolality, 455 . 565 .

$\ddagger$ Dog during urea diuresis: urine flow, 2.5 ; osmolality,

resis or low protein diet. Such analyses have been performed in a number of unoperated dogs during urea or mannitol diuresis and on low protein diets comparable to those in the experiments described in this paper. In Table VI a representative urea analysis for each category of experiment is shown. As has been true in a wide variety of states of diuresis studied in this laboratory (except when urine flow is $0.1 \mathrm{ml}$. per minute or less), the concentration of urea in the total tissue water of the papilla (including that in thinner sections taken closer to the tip of the papilla) is some 5 to 40 per cent less than the urine urea concentration. ${ }^{3}$ Thus,

\footnotetext{
${ }^{8}$ Recent experiments in this laboratory (8) have shown that when hypertonic urine passes through the ureter and bladder, particularly at flows of $0.2 \mathrm{ml}$. per minute or less, osmolality decreases, largely because of diffusion outward of urea, though smaller movements of water and electrolytes along their concentration gradients also occur. Ullrich and Jarausch (6) found that the maximum urea concentration in the papilla is usually equal to that in the urine. Urine flow was presumably low in their experiments, and urine was allowed to pool in the bladder before and for some minutes after the dogs were killed. From the data obtained in this laboratory, one would estimate that urea concentrations in urine collected in this way were 10 to 40 per cent less than in the urine leaving the kidney.

Because of the changes in urine osmolality and urea concentration in the ureter and bladder, no exact significance can be assigned to the urine concentrations at low flows given in this paper. Since these changes are increased as flow is reduced, the rises in urine concentration which actually occur when GFR is decreased in experiments like that in Table II are probably about 10 per cent greater than those found. In experiments in
}

tissue urea concentrations are very low in mannitol diuresis and on the low protein diet, moderate in urea diuresis.

\section{DISCUSSION}

In experiments at low solute excretion, urine concentration regularly fell when the filtration rate was reduced 30 per cent or more in the presence of $\mathrm{ADH}$. Similar observations were made in dehydrated dogs by Leaf and co-workers. (2). Raisz and Scheer (9) found that urine concentration fell in hydropenic man when solute excretion was decreased to very low levels. These observations are clearly the reverse of expectations derived from the usual inverse relation between solute excretion and urine concentration. In the present experiments, moderate decreases in effective renal blood flow (PAH clearance) accompanied the decreases in GFR. However, comparable reductions of renal blood flow occurred during experiments involving mannitol and urea diuresis, in which urine concentration always increased. In one experiment during urea diuresis, renal blood flow in the right kidney was reduced more than 90 per cent when the artery cuff was inflated, yet urine concentration became 60 per cent higher than the concentration of the urine from the left kidney. Sodium reabsorption and potassium excretion were not impaired in these experiments. These facts indicate that the decreases in urine concentration are not due to anoxia or to lack of essential substrates because of restricted blood flow. Comparable falls in urine concentration occurred when control urine concentration was anywhere in the range from 650 to $2,000 \mathrm{mOsm}$. per $\mathrm{Kg} . \mathrm{H}_{2} \mathrm{O}$. At similar control urine concentrations, urine osmolality increased or fell depending on the degree of reduction of GFR and the presence or absence of an osmotic diuretic. Thus, the initial degree of urine concentration per se was not the critical factor in these experiments.

The data presented in this paper are all consistent with, and readily explained by, the view that the formation of hypertonic urine depends on the delivery of sodium and urea to the medulla and that these are restricted when GFR is re-

which urine osmolality and urea concentration fell, such as that shown in Table III, the actual decreases are presumably about 20 per cent less than those observed. 
duced. Wirz (3) has proposed that the urine is made hypertonic in the collecting ducts by equilibration with hypertonic medullary interstitial fluid. The available evidence supports the hypothesis that hypertonicity is established in the medullary interstitial fluid by means of active transport of sodium salts in excess of water by some part of the loop of Henle, though the exact mechanism is unknown $(3,4,6) .{ }^{4}$ Ullrich and Jarausch (6) have found high concentrations of sodium in the medulla, and these results are confirmed by numerous analyses in this laboratory. For example, the concentration of sodium in the total tissue water of the papilla, as shown in Table $\mathrm{I}$, is more than twice that of plasma. Urine sodium concentration is usually much lower than the concentration in the total tissue water of the medulla, so that the latter value would be reduced by virtue of the urine contained in the medulla. Moreover, it is unlikely that the cells of the Henle loops and collecting ducts contain very high concentrations of sodium. The sodium concentration in medullary interstitial fluid is therefore probably much higher than the value found for total tissue water.

Urea concentrations in the medulla are also very high, but in our experience the concentration of urea in total tissue water is always 5 to 40 per cent lower than the urea concentration of the urine, whenever urine flow is $0.1 \mathrm{ml}$. per minute or more. The following hypothesis (4)

4 The recent finding of Gottschalk and Mylle (10) that fluid in the loop of the hamster has an osmolality close to that of capillary blood and urine at the same level in the papilla confirms the earlier observations of Wirz and co-workers (11) and is contrary to the hypothesis that the urine is progressively diluted as it traverses the loops (4). However, it is clear that the urine must already be dilute as it leaves the medulla in the ascending limb, not only because it has been found to be dilute in the first part of the distal convoluted tubules at the kidney surface (12) but because the balance of tonicities of the fluids entering and leaving the medulla requires this. During the formation of hypertonic urine, three isotonic fluids (proximal tubule fluid, isotonic terminal distal tubule fluid, and cortical capillary blood) enter the medulla. Since the urine leaves hypertonic and, rejecting the possibility of active solute or water transport by the capillary walls, the blood must leave this hypertonic area on the concentrated side of isotonicity, it follows that some hypotonic fluid must emerge from the area and that this hypotonic fluid must be that of the ascending limb of the loop. accounts for the high urea concentrations in the medulla, and in addition assigns a unique role to urea in the concentrating mechanism. Even at low urine flows, some 30 to 40 per cent of the filtered urea appears in the urine (13), whereas only 0.5 to 1 per cent of the filtered water is passed in the urine. If some urea is lost during the process of making the urine hypertonic in the collecting ducts, reasonable figures for the fluid reaching the start of the ducts would be 50 per cent of the filtered urea and 2 per cent of the filtered water. Since 50 per cent of the urea is contained in 2 per cent of the filtered volume, the urea concentration of the fluid entering the collecting system would be some 25 times the blood urea concentration. If the collecting ducts are permeable to urea as well as to water, urea will diffuse out along the concentration gradient from the fluid in the collecting ducts to the medullary interstitial fluid. As water is withdrawn from the collecting ducts into the hypertonic (sodium salts) interstitial fluid, urea concentration in the fluid within the ducts continues to rise and the situation is continuously favorable for diffusion of urea into the interstitial fluid. Because of the low effective blood flow to the medulla (probably by virtue of countercurent flow in the capillaries) (4), the urea continuously fed into the interstitial space from the collecting ducts is trapped. Therefore, the total amount of urea escaping from the collecting ducts in the steady state need not be large to maintain a high concentration in the interstitial fluid. In fact, this concentration would seem to be in the range of 60 to 90 per cent of the urine urea concentration. The urine osmolality due to this fraction of urine urea is balanced osmotically in the interstitial fluid by urea itself. Hence the active mechanism for sodium in the loops of Henle need only create hypertonicity of sodium salts sufficient to balance the osmotic effects of the rest of the urea plus that due to other urine solutes. It is emphasized that all movements of urea in this proposed mechanism are passive. By contributing a fraction of the urea with which it entered, the urine in the collecting ducts can maintain a high urea concentration in the interstitium and this can balance the osmotic effects of a large fraction of the urinary urea. The position of urea in the concentrating process is thus unique in that it can add to the osmotic pressure of the urine without 
being balanced by an osmotically equivalent amount of sodium salts in the medullary interstitial fluid.

The data presented in this paper are readily interpreted in terms of this hypothesis. When the GFR is substantially reduced during low solute excretion, higher urine to plasma gradients of urea and slower flows of tubular fluid result from the proportionately greater reabsorption of water. Back-diffusion (passive reabsorption) of urea in the convoluted renal tubule increases greatly, and very little urea reaches the collecting ducts. Therefore, the concentration of urea in the interstitial space of the medulla falls. In addition, the fraction of filtered sodium reabsorbed in the proximal tubule presumably increases when the GFR is reduced, and less is available for transport by the loops of Henle. Hence, interstitial fluid sodium concentration falls. Since the bulk of the hypertonicity of the interstitial fluid is due to urea and sodium salts, on both counts reduction of GFR during low solute excretion will result in decreased urine concentration.

When the dogs are on low protein diets, the contribution of urea to urine osmolality is relatively small even at control filtration rates. Little further fall in urine urea concentration can occur when GFR is reduced. Hence, falls in osmolality would be due only to decreased delivery of sodium to the medulla. Thus the fall in osmolality should be less on low protein than on regular diets, as was found (Figure 1).

The loop of Henle presumably reabsorbs only a fraction of the sodium which reaches it under ordinary circumstances (14). Therefore, in the experiment at low solute excretions in which the reduction in GFR was small, one might expect that even the somewhat restricted amount of sodium reaching the loop would still be sufficient to permit sodium transfer at roughly the previous rate. Similarly, only a modest reduction in the amount of urea reaching the collecting ducts would be expected. Since only a small amount of urea need move across the ducts to maintain a high medullary interstitial concentration, the urea concentration in the interstitium should be maintained. Thus a small reduction in GFR should not result in a fall in urine osmolality or in tissue sodium and urea concentrations, even when no osmotic diuretic is present. The data in Tables I and II and Figure 1 show this is the case.

During an osmotic diuresis, proximal sodium reabsorption is decreased (15), and it might be expected that adequate sodium would reach the loop of Henle to permit the usual levels of sodium in the medullary interstitium to be maintained, even in the face of marked reductions of GFR. During mannitol diuresis, the large volume of tubular fluid reaching the collecting ducts prevents urea concentration in the urine from achieving appreciable values. Since movement of urea from the tubular fluid into the medullary interstitial fluid is postulated to result from a passive process, the concentration of urea in the interstitium cannot be higher than urine concentration (Table VI). Urea concentrations in mannitol diuresis are already so low at normal filtration rates, that no significant drop in concentration can result from reduction of the GFR. During urea diuresis, a relatively large amount of urea at moderately high concentration should reach the collecting ducts even when GFR is reduced. Therefore, medullary urea concentration would not be expected to fall at reduced filtration rates. The results in Figure 3, which shows that urine osmolality does not fall even with marked reduction of GFR during osmotic diuresis, are in accord with these predictions.

When the solute load is reduced by lowering the filtration rate, the amount of water withdrawn in the concentrating process is decreased. This water must contain at least the sodium concentration of the plasma to leave the medulla in the capillary circulation. Therefore, the rate of loss of sodium (or any diffusible substance) from the medulla via a counter-current capillary flow will depend on the amount of water which must be carried out of the area in the blood (4). Assuming that sodium transport by the loops of Henle is approximately constant, the concentration of sodium salts in the medullary interstitial fluid will be inversely related to the amount of water entering from the collecting ducts. Since the urine finally comes into equilibrium with the interstitial fluid, the concentration of the urine will also be related inversely to the amount of water reabsorbed in the concentrating process. Therefore, reduction in this quantity when GFR and hence solute excre- 
tion are decreased would be expected to cause a rise in urine osmolality. When the GFR is considerably reduced at low solute excretions, however, this effect is more than balanced by the decreased hypertonicity of the medullary fluids due to inadequate delivery of sodium and urea. Therefore, urine osmolality falls. With small reductions of GFR at low solute loads, and with all degrees of reduction studied during solute diuresis, the delivery of sodium and urea are presumed to be adequate, for the reasons already stated. Therefore, in these situations urine osmolality rises when solute excretion is reduced. In accord with the role postulated for urea in enhancing urine concentration, reduction of the GFR during urea diuresis results in a greater increase in urine osmolality than during mannitol diuresis. Results somewhat analogous to those presented in this paper have been obtained in dehydrated human subjects by Levitt, Levy and Polimeros (16). When the filtration rate was reduced moderately

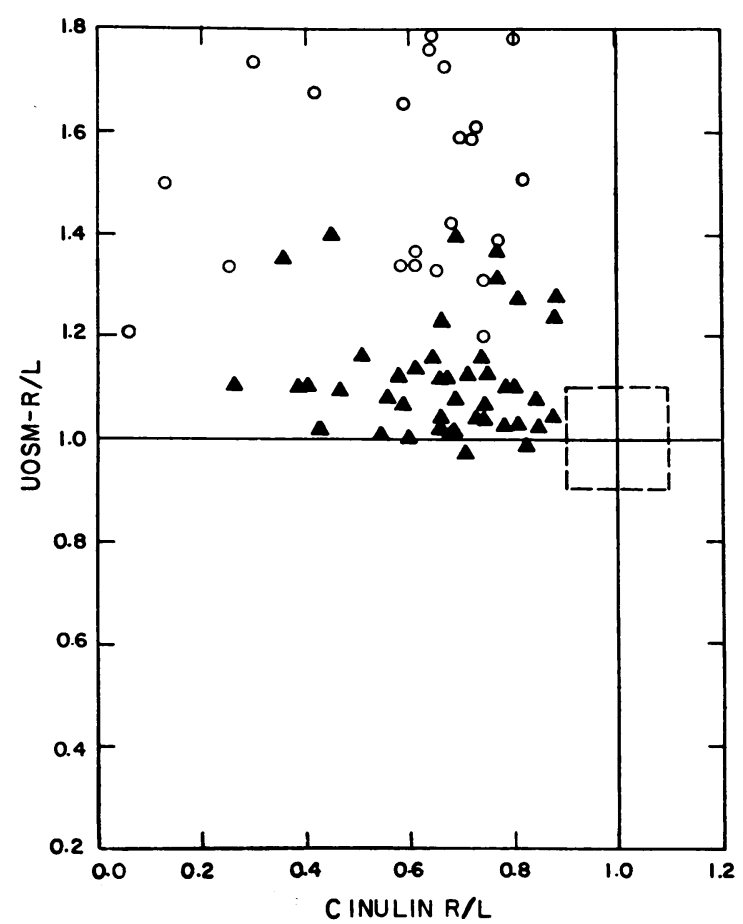

Fig. 3. Changes in Urine Concentration When the GFR Is Reduced During Mannitol Infusion (A) and During Urea Infusion (O)

The dashed lines circumscribe the area in which data from all the preliminary periods fall. in normal subjects, urine osmolality fell; in uremic subjects, similar reductions in filtration rate resulted in rises in urine osmolality.

Even at the low end of the scale of solute excretion one would expect, according to the present hypothesis, that each reduction of solute excretion would yield some further increase in urine concentration, since the amount of water moved into the medullary interstitium during the concentrating process would be progressively decreased. In the experiments reported in this paper, increases in urine concentration occurred when GFR was lowered even if control urine osmolality was in the highest range and solute excretion in the lowest seen in maximally dehydrated dogs. There was no evidence in these experiments of an approach to an "osmotic ceiling," i.e., to a fixed maximum urine osmolality or maximum urine to plasma (U/P) ratio of osmolalities, such as Smith (1) has postulated. Rather, small reductions in solute excretion at any urine concentration in the range between 800 and 2,000 mOsm. per $\mathrm{Kg} \cdot \mathrm{H}_{2} \mathrm{O}$ result in roughly comparable small increases in urine osmolality. However, some effect of small reductions in renal blood flow on urine concentration cannot be ruled out in these experiments. ${ }^{5}$ An inverse relation between urine concentration and solute excretion, even at the lower solute excretions, has also been found in man (9).

\section{SUMMARY}

The effects of reductions in glomerular filtration rate (GFR) on the elaboration of hypertonic urine have been studied in dogs in which the GFR was decreased reversibly in one kidney and urine collected separately from each kidney. When the GFR of one kidney was lowered 10 to 30 per cent in dehydrated dogs infused with vasopressin, the

5 Theoretical considerations suggest that the efficiency with which sodium salts and urea are "trapped" in the medulla is inversely related to some power (between one and two) of blood flow (4). If the medullary blood flow takes part in the slight reduction of total effective renal blood flow noted during inflation of the arterial clamp in these experiments, increased hypertonicity of the medullary fluids and consequently of the urine might occur on this basis. Since no method for measuring blood flow to the medulla is available, this possibility cannot be tested experimentally. 
concentration of the urine from that kidney often became greater than that from the control kidney by amounts up to 40 per cent. Increases in urine osmolality were noted even when control urine concentration was as high as $2,000 \mathrm{mOsm}$. per $\mathrm{Kg} . \mathrm{H}_{2} \mathrm{O}$. This indicates that the maximum urine concentrations found at very low osmolar excretions under ordinary conditions do not represent the maximum urine to plasma (U/P) ratio ("osmotic ceiling") which the kidney can achieve.

Regularly when the reduction of GFR was 30 per cent or more at low solute flows, and sometimes with smaller reductions in GFR, urine osmolality fell markedly. Under these conditions, analysis of renal tissue showed large decreases in urea concentration and moderate decreases in sodium chloride concentration in the medulla of the kidney whose GFR has been lowered. During urea or mannitol diuresis urine osmolality regularly increased, even when the GFR was reduced more than 60 per cent.

These data are consistent with the hypothesis that urine hypertonicity is developed by equilibration of fluid in the collecting ducts with hypertonic medullary interstitial fluid and that the medullary interstitial fluid is made hypertonic to plasma by deposition of sodium salts from the loops of Henle. Accumulation of urea in the medulla, considered to be the result of passive diffusion from urea-permeable collecting ducts, makes possible the achievement of considerably higher osmolalities than could be developed in response to the interstitial sodium salts alone.

\section{ADDENDUM}

Since submission of this paper our attention has been called to a paper (Miles, B. E., Paton, A., and DeWardener, H. E. Maximum urine concentration. Brit. med. J. 1954, 2, 901) in which it is indicated that the capacity to form more concentrated urine when urea is a major urinary constituent may be attributable to permeability to urea of the cells responsible for the removal of water in the production of hypertonic urine. Although this proposal does not include the essential feature of trapping the urea in the peritubular area, the other similarities to the mechanism outlined in this paper are worth noting.

\section{REFERENCES}

1. Smith, H. W. Principles of Renal Physiology. New York, Oxford University Press, 1956, p. 122.

2. Leaf, A., Kerr, W. S., Jr., Wrong, O., and Chatillon, J. Y. Effect of graded compression of the renal artery on water and solute excretion. Amer. J. Physiol. 1954, 179, 191.

3. Wirz, H. The location of antidiuretic action in the mammalian kidney in The Neurohypophysis, $H$. Heller, Ed. New York, Academic Press Inc., 1957, p. 157.

4. Berliner, R. W., Levinsky, N. G., Davidson, D. G., and Eden, $M$. Dilution and concentration of the urine and the action of antidiuretic hormone. Amer. J. Med. 1958, 24, 730.

5. Berliner, R. W., and Davidson, D. G. Production of hypertonic urine in the absence of pituitary antidiuretic hormone. J. clin. Invest. 1957, 36, 1416.

6. Ullrich, K. J., and Jarausch, K. H. Untersuchungen zum Problem der Harnkonzentrierung und Harnverdünnung. Pflüg. Arch. ges. Physiol. 1956, 262, 537.

7. Conway, E. J. Micro-Diffusion Analysis and Volumetric Error. London, Crosby, Lockwood and Son, Ltd., 1957.

8. Levinsky, N. G., and Berliner, R. W. Amer. J. Physiol. In press.

9. Raisz, L. G., and Scheer, R. L. Impairment in renal concentrating capacity with heavy exercise. Clin. Res. Proc. 1957, 5, 203.

10. Gottschalk, C. W., and Mylle, M. Evidence that the mammalian nephron functions as a countercurrent multiplier system. Science 1958, 128, 594.

11. Wirz, H., Hargitay, B., and Kuhn, W. Lokalisation des Konzentrierungs-prozesses in der Niere durch direkte Kryoskopie. Helv. physiol. pharmacol. Acta 1951, 9, 196.

12. Wirz, $H$. Der osmotische Druck in den corticalen Tubuli der Rattenniere. Helv. physiol. pharmacol. Acta 1956, 14, 353.

13. Shannon, J. A. Glomerular filtration and urea excretion in relation to urine flow in the dog. Amer. J. Physiol. 1936, 117, 206.

14. Gottschalk, C. W., and Mylle, M. Micropuncture study of osmolality of renal tubular fluid in the hydropenic rat during osmotic diuresis. Fed. Proc. 1958, 17, 58.

15. Wesson, L. G., Jr., and Anslow, W. P., Jr. Excretion of sodium and water during osmotic diuresis in the dog. Amer. J. Physiol. 1948, 153, 465.

16. Levitt, M. F., Levy, M. S., and Polimeros, D. Ef fect of reduction in filtered load on solute and water excretion in hydropenic man. J. clin. Invest. 1958, 37, 911. 